\title{
A disputa pelos 'principais e mais distintos moradores"

\author{
As Câmaras Municipais e os Corpos Militares
}

\section{The competition for the "main and most distinguished inhabitants"}

The Town Councils and the Military Corps

Christiane figueIREDO PAGANO DE MELLO'

Doutora pela Universidade Federal Fluminense

RESUMO Meu objetivo neste artigo é evidenciar as relações historicamente construídas entre o poder central régio e os centros de poder local, entendendo que estes configuram-se em lugares de encontro e colaboração, bem como de conflitos e divergências, entre os interesses das elites locais e os do centro. Nessa perspectiva, consideramos que, a partir da segunda metade do século XVIII, o centro de poder local a ser privilegiado e potencializado pelo poder régio português em sua Colônia americana consubstanciar-se-á nos Corpos militares, mais especificamente nos de Auxiliares e nos de Ordenanças.

Palavras-chave militarização, elite local, câmaras municipais, centralização política

Artigo recebido em: 25/08/2004 - Aprovado em: 15/12/2004.

Bolsa Recém-Doutor financiada pelo CNPq na Universidade Federal de Ouro Preto -UFOP. Doutora em História pela Universidade Federal Fluminense - UFF. Este artigo faz parte da minha tese de doutorado intitulada Os Corpos de Auxiliares e de Ordenanças na Segunda Metade do Século XVIII. As Capitanias do Rio de Janeiro, São Paulo e Minas Gerais e a Manutenção do Império Português no Centro-Sul da América, UFF, 2002 (mimeo). 
ABSTRACT This article aims at highliting the historically built relationships between the central power and the centers of local power, understanding that these become places of encounter and collaboration, as well as of conflicts and dissonances among the interests of the local elites and those of the center. In this perspective, we consider that, as from the second half of the XVIIIth century, the center of local power to become priviledged and potentialized by the Portuguese royal power in their American colony will turn out to be the military Corps, more especifically the Corps of Auxiliaries and the Corps of Ordinances.

Key words militarization, local elite, municipal chambers, political centralization

\section{A Centralização: As Câmaras e as Elites Locais}

Em total acordo com os postulados de centralização e racionalidade próprios do absolutismo pombalino, e adotando uma estratégia de reorganização metropolitana e colonial, a política ultramarina do reinado de D. José repercute-se nos vários espaços do Império português, entre eles o Estado do Brasil. Em termos gerais, podemos afirmar que as reformas político-administrativas de cunho centralizador implementadas visavam, inclusive na América portuguesa, "(...) exterminar todas as manifestações de pluralismos políticos, reduzindo os anteriores pólos políticos (pelo menos os mais visíveis) a simples delegações do poder do centro". (HESPANHA, 1995: 168)

A principal reforma político-administrativa durante o consulado pombalino ocorreu com a implementação de um conjunto de novas medidas que visavam a reorganização do principal órgão municipal da Colônia, as Câmaras Municipais. Tais medidas, com vistas à maior eficácia que se impunha à administração regional, inseriam-se nos planos centralizadores de Pombal, os quais podem ser traduzidas como o apogeu do processo de redução da importância e independência de que dispunham os concelhos coloniais, "quer no governo político dos colonos, quer nas suas funções administrativas e financeiras". (BICALHO, 1998: 382)

Cabe destacar, a princípio, o significativo lugar ocupado pelas Câmaras na sociedade colonial, visto "que constituíam a verdadeira e quase única administração da colônia", (PRADO, 1977: 29) o que, conseqüentemente, Ihes conferia considerável poder de influência e prestígio, tanto a nível local, quanto em sua relação com o poder central, a Coroa.

De acordo com o que afirma Maria Fernanda Bicalho como exemplo da relevância de suas atribuições a nível local: 
(...) as Câmaras coloniais foram, durante todo o século XVII, órgãos fundamentais no gerenciamento de boa parcela das rendas - tributos e donativos - coloniais. Cabia-Ihes (...) arcar quase que inteiramente com os custos da defesa, recaindo sobre suas rendas — ou sobre as rendas por elas arrecadadas - a obrigatoriedade do pagamentos dos soldos das tropas e guarnições, a construção e o reparo das fortalezas, o apresto de naus guarda-costa contra piratas e corsários, e manutenção de armadas em situações especiais e momentos de perigo, a responsabilidade pelas obras públicas e outros melhoramentos urbanos. (Bicalho, 1998: 331)

E, ainda, um outro aspecto, bastante interessante, capaz de revelar a dimensão da influência de que dispunham as Câmaras coloniais, quando consideradas em sua relação com o poder central,, "vemos as câmaras (...) proporem e recusarem tributos reais, (...) chegam a suspender governadores e capitães, nomeando-lhes substitutos, e prender e por a ferro funcionários e delegados régios" (Prado, 1977: 29). De acordo, portanto, com o que Boxer havia avaliado a respeito da atuação da Câmaras coloniais: "raramente se tornaram meros carimbos de borracha e acríticos perante os funcionários superiores do Governo, quer se tratasse de vice-reis ou de juízes do supremo" (1969: 305-329). Dessa forma, podemos concluir com Caio Prado Jr., a evidência do "poder incontrastável das Câmaras" (1977: 30).. dentro das normas da administração colonial.

Entretanto, já em fins do século XVII, por meio das medidas implementadas pela Coroa portuguesa, é possível constatar seu objetivo de diminuir o significado e a independência deste que é o principal órgão municipal da Colônia. Uma das primeiras medidas nesse sentido foi a instituição, em 1699, do cargo de juiz de fora nas principais cidades marítimas, o que, segundo Maria Fernanda Bicalho, reflete "a necessidade sentida pela Coroa de intervir nas funções administrativas e financeiras - especificamente tributárias - das Câmaras coloniais — no sentido de controlar os "descaminhos' e os possíveis prejuízos da Real Fazenda (...)" (1998: 331). Analisando, ao longo do tempo, o processo de diminuição do poder das Câmaras coloniais, registra a redução, ainda mais significativa, de sua autoridade, devido

à progressiva perda que sofrera a Câmara ao longo do século XVIII da 'propriedade' que anteriormente detivera sobre os chãos urbanos significava (...)

2 Acerca desta questão, nos informa ALDEN, Dauril in Royal Government in Colonial Brazil, University of California Press, Berkeley and Los Angeles, 1968, p. 423: "The Câmaras responded to their opportunities by arrogating many privileges and powers to which they had dubious right. While posing as champions of the people, they repeatedly ousted unpopular missionaries and royal official, and sometimes even lectured royal governors on their duties". Cita como exemplo: "The Câmaras expelled the unpopular Jesuits from São Paulo and Santos (1640-1651), the hated Sá dynasty from Rio de Janeiro (1660), the governor of Pernambuco in 1666, and removed circuit judges (ouvidores) from Espírito Santo (1659), Itamaracá (1664), and Itanhaén (1670)". 
a perda de um poder concreto - um dos únicos que lhe restara - de controle, regulação, administração e 'polícia' não apenas do espaço físico da cidade, mas ainda das suas atividades econômicas (1998: 382).

O conjunto de medidas implementadas pela Coroa "representou um processo que iria culminar, durante o século XVIII, com novas e sucessivas medidas, entre elas a passagem da grande maioria dos contratos e tributos administrativos pelas municipalidades para a jurisdição da Fazenda Real" (1998: 332). A partir da segunda metade do século XVIII, as medidas implementadas pela política pombalina atingem sua maior expressão e intensidade, repercutindo-se nos municípios por intermédio de três instituições que, apesar de sua antiguidade, surgem em seu pleno vigor. Referimo-nos às figuras do juiz-de-fora, do corregedor e do ViceRei, além dos Capitães-Generais. E conforme destaca Hespanha:

no relacionamento entre as Câmaras e o poder central, ao longo dos séculos XVI-XVIII, não podemos descurar o avanço das concepções monistas acerca do poder político. Assim, a concepção segundo a qual os concelhos eram cargos políticos autônomos, dotados de um poder originário e não dependente da outorga ou da superintendência régia vai cedendo, progressivamente, espaço à teoria da origem delegada de toda a jurisdição (1982: 251).

Sintetizando o ápice das mudanças político-administrativas atingido no reinado de D. José, citamos Caio Prado Jr:

As figuras dos governadores e demais funcionários reais começam a emergir do segundo plano a que até então tinham sido relegadas. Em sentido inverso e correspondendo a esta consolidação crescente da autoridade real cerceiam-se as atribuições das câmaras municipais, até então soberanas. O poder delas vai dando lugar ao da metrópole (1977: 40).

No entanto, há ainda que se destacar um outro aspecto de grande relevância: essas reformas, uma vez efetivadas na colônia, atingiram o centro nervoso sobre o qual, segundo Boxer, se sustentava o Império português na América, isto é, as Câmaras Municipais (1969:305-329), canal pelo qual a Coroa se mantinha em contato com as estruturas político-administrativas locais.

É oportuno lembrar que as Câmaras se configuravam como o espaço privilegiado de negociação com o poder real. Nesse espaço se viabilizava concretamente o pacto, isto é, a relação bilateral, naturalmente assimétrica pela diferença de escala, de troca entre o compromisso de obediência e fidelidade dos súditos à Coroa, e a proteção e manutenção das propriedades e privilégios da elite local, os agentes políticos da sociedade colonial.

Seguindo o programa de governo estabelecido pela Coroa portuguesa de maior centralização político-administrativa na América coloni- 
al, os representantes do poder real na Colônia atuaram no sentido de enfraquecer o poder político-administrativo das Câmaras Municipais. No entanto, é preciso lembrar que, se houve um processo de restrição da força dos governos municipais, as elites locais não perdem completamente seu poder sobre as comunidades, continuando a desempenhar um papel político de primeiro plano e conservando, ainda, um apreciável grau de autonomia.

Um aspecto a ser observado, e que põe em evidência as significativas margens de manobra política de que ainda desfrutavam as elites locais, os capitães das tropas de Ordenanças e de Auxiliares, foi a conduta de resistência passiva com que estes oficiais de altas patentes da vila de Ilha Grande, na Capitania do Rio de Janeiro, por exemplo, atenderam aos apelos dos enviados da Coroa, solicitando sua contribuição com um determinado número de escravos para o trabalho nas reformas das fortificações da vila. Como não conseguiram reunir o número de escravos estipulado, o responsável pela condução das reformas, Antonio Lopez de Barros, foi então responsabilizado pelos atrasos nas obras, pelo que se desculpa e se defende expondo os problemas que enfrentava ao Brigadeiro Pedro Álvares de Andrade, encarregado pelo Vice-Rei Conde de Resende da defesa da região e supervisão das reformas:

IImo. Snro. Brigadeiro, As minhas imensas faltas, que eu tenho experimentado, dos escravos com que contribuem os moradores destes distritos para o trabalho das Fortificações desta Villa, e isto desde que estou encarregado, me fazem passar pelo grande desgosto de não poder adiantar estas obras, como desejo: Tenho feito todas as diligencias para as evitar, tendo requerido vivamente e por muitas vezes ao Sargto. Mor Come. as providências precizas para o dito fim; mas não tendo conseguido melhoramento algum, sou obrigado a pôr o referido na presença de V.Sa.(...) (Arquivo Nacional do Rio de Janeiro - ANRJ, Caixa 484, pacote 1, Carta de 9 de novembro de 1794).

Considerando indiscutível uma intervenção política mais acentuada por parte do governo português na administração colonial, afastamonos, porém, das análises que tendem a ver os centros de poder local como meros executantes dos interesses do poder central, uma vez que tal concepção nos levaria a perder de vista a especificidade de sua função enquanto agentes locais. Ainda que não totalmente independentes de condicionamentos externos, mesmo ante a constatação de uma iniciativa necessariamente mais centralizadora, forçamo-nos a crer não devam ser os centros de poder local a esta redutíveis de forma mecânica. É nosso objetivo destacar tais centros de poder não meramente como forças determinadas pelo governo central, mas, também, e sobretudo, como interlocutores e intermediadores, a partir do espaço que dominam e que Ihes é próprio: a comunidade local. 
Entendemos que, da política intervencionista implementada pela Coroa portuguesa na América colonial não decorrem relações verticais e dicotômicas muito bem definidas, mas, sim, uma nova articulação entre o local e o central, viabilizando, inclusive, a potencialização de um outro centro de poder local, o militar, capaz de englobar grande parte dos membros que compõem as elites coloniais e que, portanto, se estendia numa malha contínua, por todo o território.

Sendo nosso objetivo evidenciar as relações historicamente construídas entre o poder central e os centros de poder local, entendemos que estes configuram-se em lugares de encontro e colaboração, bem como de conflitos e divergências, entre os interesses das elites locais e os do centro. Nessa perspectiva, consideramos que, a partir da segunda metade do século XVIII, o centro de poder local a ser privilegiado e potencializado consubstanciar-se-á nos Corpos militares, mais especificamente nos de Ordenanças e nos de Auxiliares.

\section{A disputa pelos 'principais e mais distintos moradores'}

Consideremos, primeiramente, a crescente importância dos territórios ultramarinos na aguerrida disputa travada entre as potências européias pela hegemonia mundial. Tal conflito, inequivocamente, sustentava, em primeiríssimo plano, o problema da preservação dos territórios coloniais. Cabe mencionar, ainda, a progressiva consolidação da autoridade metropolitana na administração colonial, resultando no conseqüente decréscimo do poder político de que, até então, dispunham as Câmaras Municipais, poder esse consubstanciado no espaço tradicionalmente privilegiado de negociação com o governo central. Partimos do princípio que, a partir de tal quadro, ocorreu de um processo de ativação, pelo poder central, das organizações militares coloniais, os Corpos de Auxiliares e de Ordenança, enquanto locus em que os interesses das elites locais revestir-se-iam de maior destaque, constituindo-se seus oficiais de alta patente em detentores de um maior poder de barganha frente ao governo central.

Primeiramente, no que concerne aos conflitos europeus pela conquista, ou manutenção, de mercados no além-mar, procederemos a uma breve análise. Cumpre destacar que a Portugal impunha-se a necessidade de aumentar sensivelmente a capacidade defensiva de seus domínios na América, em decorrência da Guerra dos Sete Anos (1756-1763), momento em que "as competições coloniais, foram então levadas ao climax" (NOVAIS, 1983: 47). A Guerra dos Sete Anos, como sabemos, basicamente uma disputa entre as duas maiores potências da época, Inglaterra e França, pelo controle de territórios na América e na Índia, envolveu, conseqüentemente, as nações ibéricas - a Espanha aliada à França, e Portugal, subordinado à esfera de influência inglesa. 
Após o estabelecimento dos Estados Ibéricos em campos opostos nesse novo conflito europeu, a contenda entre Portugal e Espanha logo se prolongaria avançando para as indefinidas regiões fronteiriças sulinas. Vale notar que, como observa Fernando Novais,

ao lado das zonas de tensão entre as potencias dominantes em luta pela hegemonia, França e Inglaterra, entre os países coloniais ibéricos se vão formando ao mesmo tempo outras zonas de tensão (sobretudo a região platina). Os dois tipos de conflitos correm paralelos, e se inter-relacionam continuamente (...) (Idem: 47).

No caso português, especificamente, o conflito com a Espanha pelos territórios às margens do rio Uruguai havia demonstrado claramente a precária capacidade de resistência de seu exército, sobretudo quando da invasão e conquista espanhola da Colônia do Sacramento, em dezembro de 1762, bem como da vila do Rio Grande e da margem norte do canal que conectava a Lagoa dos Patos ao mar. Através do Tratado de Paz de 1763, dando por encerrada a Guerra dos Sete Anos, restituía-se a Portugal a Colônia do Sacramento; todavia, os espanhóis continuaram a sustentar que os territórios à volta da Colônia Ihes pertenciam. Assim, Portugal perdera o Rio Grande de São Pedro com seu território, bem como as ilhas de Martim Garcia e das Duas Irmãs.

Com o intuito de aumentar a capacidade defensiva portuguesa na América uma série de medidas foram implementadas. Podem-se citar, entre outras, a transferência, em 1763, da capital do Estado do Brasil para o Rio de Janeiro, mais próximo das regiões auríferas e mais apto a coordenar as ações militares que se prefiguravam ao Sul do Estado; o envio de regimentos militares portugueses para o Rio de Janeiro e posteriormente para o Sul; e a recriação da Capitania de São Paulo.

Cumpre destacar que, no concernente à política de defesa da América portuguesa, implementada a partir da segunda metade do século XVIII, não obstante houvesse toda uma atenção da Coroa portuguesa no que diz respeito à construção e reparo de fortalezas, quartéis e armazéns, pode-se verificar uma maior ênfase não só na formação, como também na multiplicação dos Corpos militares, constituídos basicamente pela população colonial, como o foram os Corpos de Auxiliares e de Ordenanças, cada vez mais reputados pela Coroa como elemento indispensável na defesa e manutenção de seus domínios. ${ }^{3}$

3 No que se refere à política defensiva implementada pela Coroa portuguesa a partir da segunda metade do século XVIII, na qual veio a creditar às 'forças da colônia' como estrategicamente mais fundamentais para a segurança do território colonial em relação ao fortalecimento das estruturas de fortificação até então preponderantes, consultar BICALHO, Maria Fernanda: A Cidade e o Império: O Rio de Janeiro na dinâmica Colonial Portuguesa. Séculos XVII e XVIII, São Paulo,. USP, 1998, (mimeo), p. 92-95. 
Em meio a este clima de crescente antagonismo, em que não somente a segurança, mas, ainda, a própria existência, de seus domínios ultramarinos estavam em jogo, fazia-se imprescindível, para a Coroa portuguesa, assegurar a fidelidade de seus súditos coloniais. A nosso ver, os Corpos de Auxiliares e Ordenanças, constituir-se-iam no lugar de encontro e canal primordial por meio do qual se efetivaria a colaboração entre o poder local e o governo central.

Seguimos, como orientação norteadora deste trabalho, a formulação de que os vínculos políticos entre Metrópole e Colônia se estabeleciam a partir de uma lógica contratual cuja dinâmica das negociações e trocas alimentava continuamente o pacto entre estas forças complementares, embora assimétricas. Esta rede de relações e negociações, responsáveis pela sustentação dos vínculos entre a Metrópole e a Colônia, era regida por regras e princípios marcados pelos valores de uma sociedade estamental, valores esses que regulavam os interesses de ambas as partes, bem como a busca de um consenso. É sob essa perspectiva que, no contexto da sociedade colonial, buscaremos compreender a inserção dos corpos de Ordenanças e de Auxiliares.

Nesse sentido, importante é ressaltar os privilégios de que dispunham e gozavam os eleitos para os postos de oficiais dos Corpos de Ordenança e de Auxiliares. Concedidos pela Coroa, tais privilégios bem podem ser constatados pelas palavras referidas em suas patentes: "E com esta gozarão todas as honras, liberdades, franquesas, privilegios e izenções que Ihes pertencem". Equivale a dizer que "Todo o Militar goza de nobreza pelo privilegio de foro, que Ihe pertence por Direito Civil; e quando he oficial de patente, escritas as palavras referidas nellas declaradas, e assignadas pela Real Mão, tem toda a graduação de nobreza." (VERÍSSIMO, 1816: 60). Assim, além do título de nobreza de que dispunham os oficiais de Ordenanças e Auxiliares, a estes últimos eram ainda concedidos privilégios e imunidades idênticos àqueles gozados no Reino pelas tropas pagas.

Dentre os privilégios concedidos aos oficiais das Ordenanças, pode-se citar "que os Capitães-Mores, e mais Capitães lograssem os privilégios de Cavaleiros Fidalgos" (Idem: 61). Estes, somados aos demais oficiais maiores, não deviam ser obrigados a servirem nos "cargos da República de menos qualidade", nem, tampouco, a "darem alojamento" (Idem). Estavam, ainda, isentos da obrigação de "ir às fronteiras a gente de Ordenança". Tampouco, podiam "ser prezos em ferros senão por crime que por ele mereção morte civil, ou natural" (Idem).

Dentre as vantagens e privilégios desfrutados pelos oficiais dos Corpos de Auxiliares, e o conseqüente prestígio social deles decorrentes, podemos citar, além das recompensas, com hábitos e tenças, 
àqueles que prestassem serviços militares, também, o privilégio que Ihes garantiam a proteção contra injunções tributários: "serão isentos de contribuírem com fintas, taxas, e outros encargos, ou tributos impostos pela Câmara" (Idem), a prerrogativa de usufruírem de ampliada segurança econômica: "estes não podem ser penhorados por bens do seu uso nem presos por dívidas" (Idem). Também nas questões judiciais desfrutavam de regalias: "só os poderão prender imediatamente nos casos de flagrante delito", não devendo ser "prezo na enchovia e dar-se-Ihe-há sempre prizão mais decente" (Idem). Em casos criminais, deveriam ser julgados apenas em tribunais especiais. Tais privilégios, entre outros mais, foram concedidos pelo "Alvará dos Privilégios dos Auxiliares de 1645", e confirmados pelo "Decreto ao Desembargo do Paço em que Sua Majestade ordena se observem inviolavelmente os privilegios dos Auxiliares de 1751" (1777: 260 a 267).

Cumpre destacar, no entanto, que, embora o Decreto emitido no ano de 1751 venha a confirmar todos os privilégios já concedidos pelo Alvará de 1645 aos oficiais das Tropas de Auxiliares, o Decreto, ao contrário do Alvará, se detêm mais especificamente em um dos privilégios concedidos, qual seja, a isenção daqueles oficiais militares de servirem nos cargos da República. Tal reiteração parece ser indicativa de que esse privilégio, particularmente, não vinha sendo devidamente respeitado. Parece expressar, ainda, a disposição da Coroa em impor sua premente execução, julgada necessária em prol do bom funcionamento dos corpos militares de cujo excelente desempenho dependia a conservação e a segurança de suas conquistas ultramarinas. Dessa forma, o Decreto é absolutamente categórico ao determinar àqueles que estivessem servindo nos cargos da República, e que fossem oficiais de Auxiliares, que se retirassem daqueles cargos para servirem apenas em suas respectivas tropas: "mando recolher os ditos oficiais [de Auxiliares] e soldados [pagos] aos seus respectivos corpos para os exercitarem com a disciplina militar, que he tão necessária para a conservação e reputação das tropas e para a segurança dos meus Reinos e vassalos delles" (Idem: 266 a 267).

Assim, da impropriedade de se exercerem ambas as funções — civil e militar - simultaneamente, da coação sofrida por oficiais Auxiliares a servirem nos cargos da República, e da primazia das funções militares com relação às civis, conforme visto na citação acima, dispõe o Decreto Régio datado de 23 de março de 1751:

a experiencia havia mostrado que de se obrigarem os Oficiaes militares e soldados pagos e auxiliares a servirem os cargos da República nas terras em que tem seus domicílios, resultarão inconvenientes (...). Hei por bem ordenar, que os ditos oficiaes e soldados assim pagos como auxiliares sejão isentos 
de todos os empregos civis e cargos da Republica, para não serem constrangidos a servirem nelles involuntariamente, e restituindo a toda a sua integridade os privilégios dos sobreditos (...) (Idem).

Muito embora confirmados os privilégios dos Auxiliares em 1751, com destaque especial ao de isenção de servirem nos cargos da República, o que se pode verificar é que tal privilégio fora responsável por provocar inúmeras tensões entre as Câmaras e aqueles Corpos, posto não terem sido poucas as vezes em que os oficiais Auxiliares foram convocados para os cargos concelhios.

Muitos deles, apoiados em seus privilégios, se negavam a servir nas Câmaras, alegando, como por exemplo, o requerimento feito pelos Oficiais dos Terços dos Auxiliares da Capitania do Rio de Janeiro:

Dizem os officiaes dos Terços dos Auxiliares da Capitania do Rio de Janr. ${ }^{\circ}$, q' attendendo os Snres Reys deste Reyno aos trabalhos, q' padecem, e ao serviço, q' fazem no tempo da Guerra em defeza do mesmo Reyno, expondo as suas vidas nas Front. ${ }^{\text {as }}$, forão servidos conceder-lhes os privilegios, q' se offerecem, os quaes forão mandados observar por Real Decreto de 22 de Março de 1751: mas he grande a oppressão q' fazem aos supp. ${ }^{\text {tes }}$, pois dezattendendo-lhes os seus privilegios, os obrigam como se privilegiados não fossem, a sofrer varios encargos contra elles. E por q' mesmo he V. ${ }^{a}$ Mage. de servido conceder aos supp. ${ }^{\text {es }}$ todos as izenções, de q' gozão os soldados pagos, e estrangros, os quaes são explicitam . te izentos de todos os empregos civis e cargos da Republica. (Arquivo Histórico Ultramarino - (AHU), Rio de Janeiro, Avulsos, (Caixa) Cx 75, (documento) doc. 70, 13/9/17634)

Sobre a apelação dos suplicantes recaiu um despacho do Rei: "Ihes façam m. ${ }^{c e}$ em observancia dos d. ${ }^{o s}$ privilégios". É possível perceber argumentos semelhantes em outro requerimento feito por um oficial de Auxiliar da Capitania de São Paulo a D.José I:

(...) querem obrigar ao Supp. ${ }^{e}$ a todos os cargos da Republica, sem atenderem a q' o posto de Sarg ${ }^{\text {to }}$ mor q' exercita hé izento de semelhante ocupação (...), querendo por este modo enterromper, os privilégios, Liberdades e izenções, q' V.Mage foi servido conçeder a todos os melitares q' os servem (AHU, São Paulo, Avulsos, cx 20, doc. 19232, Requerimento de 4 de abril de 1751)

Da mesma forma, o requerimento do capitão de auxiliares, Antonio de Sousa de Morais, da Freguesia de Moji das Cruzes da Capitania de São Paulo, solicita ao governador que se proceda a nova eleição de barrete, em virtude de não poder exercer ao mesmo tempo aquela ocupação e a de juiz ordinário para que tinha sido, ultimamente, nomeado.

Diz o Capitão dos Auxiliares (...) q'abrindo-se os Pelouros dos Officiaes da Camara, que havião servir o anno futuro de 1771 nele sahio o Suplicante por Juiz ordir. ${ }^{\circ}(. .$.$) . Sendo o Sup. { }^{e}$ pelos privilegios q' Sua Real Mag. ${ }^{e}$ concede 
aos capitaes, tanto das companhias de cavallo, como de pé, exentão ao Sup. ${ }^{e}$, pois não pode sevir em o mesmo tip. ${ }^{\circ}$ duas ocupaçoens publicas, por

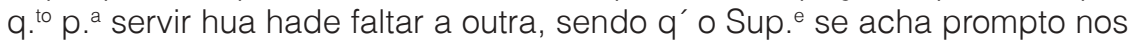
exercicios Militares (...). (AHU, São Paulo, cx 27; doc 2546, 15/12/1770)

Através das representações feitas pelas várias Câmaras ao rei D.José I, concernentes a esse privilégio, pode-se perceber, em primeiro lugar, a tentativa dos camaristas em deter as ameaças que, pela emergência de vários Corpos de Auxiliares justificados pelas necessidades bélicas, bem como os privilégios deles decorrentes, pairavam sobre a composição interna dos governos concelhios.

Nestes termos, dentre as inúmeras críticas feitas por seus vereadores contra o privilégio de isenção dos Auxiliares, a mais recorrente era a falta de pessoas qualificadas a ocupar os "cargos da República", posto que a disputa que se abria entre as Câmaras e os Corpos de Auxiliares pelos "principais e mais distintos moradores" (AHU, S.P, Avulsos, cx 31, doc. 2762, 3/7/1777) tornava evidente a nítida preferência destes pelos cargos militares.

Nesse sentido, podemos citar a representação da Câmara de Angra dos Reis, no Rio de Janeiro, ao Vice-Rei, protestando contra o requerimento de um oficial Auxiliar que havia solicitado a sua isenção do cargo de vereador ${ }^{4}$

(...) hé costume nesta Villa servirem os Officiaes Auxiliares nos cargos deste Senado por ser terra piquena, e não aver quem posa servir os cargos da Republica, concorrendo serem presiso servirem a maior parte dos Officiaes Auxiliares. (Arquivo Nacional do Rio de Janeiro (ANRJ), Avulsos, cx.500, pc.1 (pacote) 'Senado da Câmara do Rio de Janeiro, Angra dos Reis, 20/9/1794')

Sobre a apelação do suplicante recaiu o despacho: "Seja serv. do attendendo ao privil. ${ }^{\circ}$ concedido ao Sup. e, como Off. ${ }^{\text {al }}$ Aux. ${ }^{\text {ar }}$ havelo por escuso, em dar em seo Lugar outro nome como he estilo. (Idem).

Já os oficiais da Câmara de São Paulo, em representação ao rei D.José de 5/12/1770, expõem a falta de vassalos beneméritos nos empregos da Câmara e suas consequências para o bem comum da Comarca. Alegam que o motivo para tal situação é o privilégio que dispõe os Auxiliares. Enviam, ainda, uma cópia da representação de seus anteces-

4 Diz o Ten.te Duarte Jose da Costa, que estando em actual serviço de S. Magestade no exercicio do Posto de Aju.te, pelo impedim.to deste, foi nomeado vereador da Camara da Villa de Angra dos Reis, com o q' será o sup.te embaraçado p. a bem servir, e desempenhar as obrigaçoens do lugar e posto militar, de q' fora imcumbido; ao m.mo passo q' m.tos outros podem servir com mas aptidão o lugar de vereador: E por q'S. Mage concede ao Sup.e, e mais oficiais Auxiliares o privilegios de serem izentos deste onus publico; recorre o Sup.e a V.Ex.a p.a q' se digne haver ao Sup.e escuzo, mandando que no seo impedim.to nomeem os vereadores algum outro, que possa servir. (ANRJ, Avulsos, Cx.500, pc.1 'Senado da Câmara do Rio de Janeiro, Angra dos Reis, 20/9/1794') 
sores, ${ }^{5}$ datada de 1767, na qual seus oficiais pediam providências sobre a isenção para não servirem os cargos da República os que eram oficiais dos Regimentos de Auxiliares. A representação da Câmara de 1770 constata e clama por soluções:

Depois que nesta Cidade, Freguezias do seu termo, e nas villas desta Comarca, se creo, no anno de 1766 o corpo das Tropas, que formão dous Regimentos de Auxiliares (...) privilegiados para não serem constrangidos a servir na Republica, nem os Officiaes, nem os Soldados; totalmente ficou a Camara desta Cidade destituhida dos sogeitos beneméritos (...); e ficão faltando para o serviço de V.Mage, e o do bem comum da utilidade publica, os mesmos, que como bons vassallos devião ser os primeiros para os empregos da Camara. Esta dezordem, obrigou aos nossos antecessores por na Prezença de V.Mage ${ }^{e}$, em conta que derão em 19 de Dezembro de 1767, que repetimos por cópia; para que se digne V.Mag. ${ }^{e}$ mandar prôver de remedio, que for mais do Real Agrado. (AHU, São Paulo, Avulsos, cx 27, doc. 2532, 5/12/1770)

Em outra representação ao rei D.José, os oficiais da Câmara de Santa Ana de Moji das Cruzes, na Capitania de São Paulo, protestam contra as desordens e o desprezo pelas Leis que reinam na vila, alegando que:

Quando as principais e distintas pessoas desta V. ${ }^{a}$ ocupavão nas Camaras os Cargos della sempre os Povos cumprirão em tudo com os deveres da Sua obrigação (...) não tendo esta Camara a quem mais eleger para ocupar tais empregos, com aquellas circunstancias, e merecim. ${ }^{\text {tos }}$ correspondentes as mesmas ocupações, o fazem com sujeitos pobres (...). E porque o remedio desta dezordem só consiste com que V.Magde determine por Sua Real Ordem, que os tais Auxiliares se não valhão dos Privilegios a que se pejão para serem os cazos de exercer os cargos da Camara da Republica desta Villa (...) que para ocupar os empregos da Camara e de Juiz Ordinario desta Villa sejão (...) os principais e mais distintos moradores dellas inda que Auxiliares sejão (...) (AHU, S.P., Avulsos, cx 31, doc. 2762, 3/7/1777).

Por outro lado, a posição do Capitão-General de São Paulo, Morgado de Mateus, com relação às Câmaras, e que podemos tomar como exemplo, porventura extremo, do 'espírito' que presidia o comportamento da Coroa e de seus representantes ultramarinos, empenha-se em demonstrar que era nas Câmaras da Capitania que se concentravam os que "se utilizão, descanção, e governão", em contraste com as Companhias e Regimentos militares, onde se encontravam os que "gastão, trabalhão e obedecem" (Documentos Interessantes para a História de São Paulo - DIHSP, vol.XIX: 81 a 83, apud Leonzo, 1979: 228.).

5 "(...) e quando alguns eleitos para os dictos ministerios se querem escuzar, com qualquer requerimento, que fazem ao Governador, os manda izentar; não havendo por este motivo, quem possa servir nas Camaras e nos mais officios dellas, por que todos os moradores desta Cidade, e da Villas e Freguezias da Comarca se achão listados por soldados Auxiliares (...)".(AHU, São Paulo, Avulsos, x 27, doc. 2532, 5/12/1770) 
Visando reforçar a identidade das hierarquias social e a militar, afirma D. Luis Antonio de Souza: "(...) entre todos os serviços hé o das Armas o mais distinto, em o qual sempre se ganharão as mayores glorias, e os mayores premios, e quem nelle se emprega deve ser preferido nas honras, e nas recompensas" (DIHSP, vol. XXIII: 132, apud Leonzo, 1979: 229).

Nesse sentido, vale observar, ainda, uma interessante consideração feita pelo Ministro e Secretário dos Negócios Estrangeiros e da Guerra do Reino de Portugal, D.Luiz da Cunha, em suas Maximas Discretas, sobre a Reforma necessária da Agricultura, Comercio, Milicia, Marinha, Tribunáis, Fabricas de Portugal (Biblioteca Nacional de Lisboa - BNL, Coleção Pombalina - PBA, 460: 204). Em seu discurso, operando com a comparação entre Inglaterra e França, articula suas diferentes formas de governo ao conseqüente lugar em que nelas ocupam as organizações militares, apontando, assim, os motivos político-militares pelos quais os ingleses não geraram sequer um bom general: "por q' o seu ponto de vista hé de serem Parlamentarios p. a talvez forçarem o Principe, q' delles depende a lhes dar empregos Civis q' dezejão" (Idem). E, pelo contrário, em França, "onde o Parlamem. ${ }^{\text {to }}$ não tem mais influências, q' nos processos q' julga, e as armas são preferidas as Letras, de tal sorte q' a mulher do primr. ${ }^{\circ}$ Presid. te não tem lugar na Corte (...) q. ${ }^{\text {do }}$ a de qualquer Official se pode apresentar as Mag. es , e por isso estão os seus exércitos cheios de $m$. tos bons Generaes" (Idem).

Atendo-nos à nossa perspectiva de evidenciar os Corpos militares na segunda metade do século XVIII como o espaço potencializado através do qual acionam-se as principais e fundamentais negociações entre o governo central e as elites locais, partimos do princípio de que, nas representações acima citadas acerca dos Corpos de Auxiliares, faz-se possível assinalar um progressivo deslizamento do valor social dos cargos de vereança, até então os mais cobiçados pelos senhores locais, para uma "lenta militarização dos valores sociais" (Pujol, 1991: 121).

Veja-se, entretanto, que, ao afirmarmos a atuação dos Corpos militares como interlocutores privilegiados pelo poder central, não necessariamente conotamos que os Corpos militares substituíram as Câmaras enquanto agentes de negociação em nome da comunidade ou do povo, isto é, enquanto representantes do bem comum frente ao poder régio. Vale ressaltar que os Corpos militares não foram representantes do bem comum do povo, diversa sendo a natureza desse centro de poder local que, embora representasse, realmente, o bem comum, assim o fazia exatamente no nível e na medida em que, para o poder régio, constituíam-se em forças capazes de atuar na defesa dos domínios americanos, então, seriamente ameaçados.

Devemos, ainda, considerar que diante das novas diretrizes político- 
militares de intensa militarização da população masculina, quer nos parecer que o objetivo primordial de negociação, a que acima nos referimos, entre o poder central e as elites locais não poderia ser outro senão a maciça arregimentação de homens para compor os novos Corpos de Auxiliares, cuja conseqüência direta seria a geração de postos de Oficiais, a serem ocupados pelos senhores locais, com a contrapartida da concessão do muito cobiçado título de nobreza, além dos amplos privilégios e imunidades semelhantes aos desfrutados, como já visto, no Reino, pela tropa paga.

Finalmente, cabe-nos advertir que, nossa tentativa de evidenciar a política régia de estímulo ao serviço militar, especialmente aquele não remunerado — os Auxiliares e as Ordenanças — bem como de demonstrar, através da documentação, a tendência e a preferência das elites locais pelo serviço militar, não tem a intenção de exagerar a eficácia da ação do poder central sobre as comunidades locais e de suas elites. Por outro lado, também estamos longe de entender que as comunidades locais estavam fechadas sobre si mesmas, auto-suficientes. Ao contrário, acreditamos que estas evidenciam-se como um complexo tecido de relações internas e externas (Pujol, 1991: 121). Em outros termos, quando conjugamos a política de militarização da Coroa e a motivação dos senhores locais a ocuparem os postos militares, tal fato não deve absolutamente ser interpretado como ausência de resistência por parte das elites locais à política adotada pela Coroa. Sublinhemos, entretanto, que, naquele momento, grande era o poder conferido, à escala local, pelo título de oficial, além do que, era no interior do próprio espaço militar que se manifestavam as resistências mais persistentes, e eficientes, à disponibilização de forças para as longínquas fronteiras sulinas.

\section{BIBLIOGRAFIA}

ALDEN, Dauril. Royal Govermente in Colonial Brazil. University of California Press, Berkeley and Los Angeles, 1968.

BICALHO, Maria Fernanda, A Cidade e o Império: O Rio de Janeiro na dinâmica Colonial Portuguesa. Séculos XVII e XVIII. USP, 1998, (mimeo).

BOXER, C.R.. O Império Colonial Português (1415-1825). Lisboa: Edições 70, 1969.

HESPANHA, António M. História de Portugal Moderno-político e institucional. Lisboa: Universidade Aberta, 1995.

História das Instituições: épocas Medieval e Moderna. Coimbra: Livraria Almeida Editora, 1982.

LEONZO, Nanci. Defesa Militar e Controle Social na Capitania de São Paulo: As Milícias, Tese de doutoramento, USP, 1979, (mimeo).

NOVAIS, Fernando. Portugal e Brasil na Crise do Antigo Sistema Colonial (1777-1808), São Paulo: Hucitec, 1983.

PRADO, Caio Jr.. A Evolução Política do Brasil e outros Estudos, São Paulo: Brasiliense, 1977. 
PUJOL, Gil Xavier, "Centralismo e Localismo? Sobre as relações Políticas e Culturais entre Capital e Territórios nas Monarquias Européias dos Séculos XVI e XVII". Penélope - Fazer e Desfazer a História, n. 6, Lisboa, 1991.

VERISSIMO, Antonio Ferreira da Costa, "Das Honras e dos Privilégios", In: Collecção Systematica das Leis Militares de Portugal, Lisboa, Impressão Regia, 1816, vol 3 "Leis Pertencentes aos Milicianos".

\section{Documentos:}

Arquivo Nacional do Rio de Janeiro - ANRJ, "Correspondência de Capitães-Mores' Caixa 484, pacote 1, Ofício de 9 de janeiro de 1794.

Arquivo Nacional do Rio de Janeiro - ANRJ, "Senado da Câmara do Rio de Janeiro" Avulsos, Cx.500, pc.1.. Representação de 20 de outubro de 1794.

Arquivo Histórico Ultramarino - AHU, Avulsos, São Paulo, Cx 20, doc. 1923, Requerimento de 24 de abril de 1751.

Arquivo Histórico Ultramarino -AHU, Avulsos, São Paulo, Cx 31, doc. 2762. Representação de 3 de julho de 1777.

Biblioteca Nacional de Lisboa - BNL, Reservados, Coleção Pombalina, PBA. 460. D. Luiz da Cunha: "Maximas Discretas, sobre a Reforma Necessária da Agricultura, Comercio, Milicia, Marinha, Tribunais, Fabricas de Portugal-Representadas e dirigidas ao Sereníssimo Senhor D.José", s/d.

Documentos Interessantes para a História de São Paulo - DISHP, vol.XIX, "Carta de D. Luis Antonio de Souza para o Conde de Oeiras sobre a conservação das tropas Auxiliares. São Paulo, 12 de novembro de 1767"

Documentos Interessantes para a História de São Paulo - DIHSP, vol. XXIII, "Circular de D. Luiz Antonio de Souza para as Câmaras da Capitania sobre as preferências que os militares devem ter para os postos da Milicia. S.P., 16 de janeiro de 1767". 